\title{
The Relationship between Physical Activity and Screen Time with the Risk of Hypertension in Children and Adolescents with Intellectual Disability
}

\author{
Justyna Wyszyńska, ${ }^{1}$ Justyna Podgórska-Bednarz, ${ }^{1}$ Katarzyna Dereń, ${ }^{2}$ and Artur Mazur ${ }^{2}$ \\ ${ }^{1}$ Institute of Physiotherapy, Medical Faculty, University of Rzeszów, Rzeszów, Poland \\ ${ }^{2}$ Institute of Nursing and Health Sciences, Medical Faculty, University of Rzeszów, Rzeszów, Poland \\ Correspondence should be addressed to Justyna Wyszyńska; justyna.wyszynska@onet.pl
}

Received 18 August 2017; Accepted 15 October 2017; Published 2 November 2017

Academic Editor: Haichun Sun

Copyright (C) 2017 Justyna Wyszyńska et al. This is an open access article distributed under the Creative Commons Attribution License, which permits unrestricted use, distribution, and reproduction in any medium, provided the original work is properly cited.

\begin{abstract}
Introduction. Children and adolescents with intellectual disability (ID) have significantly lower levels of physical activity compared to their peers without ID. Association between the level of physical activity and screen time with hypertension (HPT) in children and adolescents with ID has not been reported yet. Aim. To assess the relationship between the level of physical activity and screen time with the prevalence of HPT in students with ID. Material and Methods. The study group consisted of 568 children with ID aged 7 to 18. The control group matched for age and gender consisted of 568 students without ID. Blood pressure (BP), body mass and height, level of physical activity, and screen time were assessed. Results. The level of physical activity in the study group was significantly lower than in the control group (score 1.99 versus 3.02, resp., in Physical Activity Questionnaire). The risk of HPT in the students with ID with low levels of physical activity was more than 4 times higher $(\mathrm{OR}=4.40)$ and more than 2 times higher when screen time was $\geq 2 \mathrm{~h} /$ day. Conclusion. Low level of physical activity and long screen time were associated with significantly higher HPT risk among children and adolescents with ID.
\end{abstract}

\section{Introduction}

Low level of physical activity is responsible for more than five million deaths globally per year, being one of the most important factors for the risk of noncommunicable diseases [1]. Epidemiological evidence has revealed a consistent, temporal, and independent relationship between low level of physical activity and HPT [2]. As the prevalence of HPT is increasing worldwide, primary prevention of HPT has become an important public health initiative. Physical activity is commonly recommended as an important element of lifestyle modification, which may help to prevent HPT [3].

Data show that $80 \%$ of children and adolescents in 105 countries do not achieve the recommended level of physical activity, that is, at least 60 minutes of moderate to vigorous physical activity daily [4]. In addition, high number of children and adolescents spend more than 4 hours a day on sedentary activities, although less than 2 hours a day are recommended for screen-based entertainment (TV viewing, computer, and videogame usage) $[5,6]$. Research results showed that TV viewing and screen time were associated with unfavorable body composition, decreased fitness, lowered scores for self-esteem, and prosocial behavior [7] as well as higher systolic BP and diastolic BP in children and adolescents $[8,9]$.

Even lower levels of physical activity are observed among the population of children and adolescents with ID. Numerous studies indicate that youth with ID compared to the peers without ID have significantly lower levels of physical activity [10-13]. This is not only due to the limitations associated with ID and its consequences, but also due to numerous environmental barriers, financial limitations, lack of social support, lack of motivation, low levels of awareness, and self-efficacy [14]. Low level of physical activity and high level of sedentary behaviors in combination with genetic predisposition, level of ID, improper diet, and medication 
increase the chances of obesity, which is one of the risk factors for HPT [15].

The incidence of HPT in children and adolescents with ID is significantly higher than their peers without ID [16, 17]. This is a serious public health problem, as the results of epidemiological studies indicate that HPT in childhood is a factor that determines the incidence of HPT in later life [18]. In addition, HPT in adolescence is strongly correlated with an increase in morbidity and mortality rates in adulthood [19]. In the case of children and adolescents with different types and levels of ID, lack of activity is particularly disadvantageous as physical activity is also a part of the process of education, development, and rehabilitation [20].

We have not found any reports on the relationship between the level of physical activity and screen time with the prevalence of HPT in the developmental age population with ID.

\section{Purpose of the Paper}

Therefore, the aim of the study was to assess the relationship between the level of physical activity and screen time with prevalence of HPT in children and adolescents with ID.

\section{Material and Method}

The study was approved by the Bioethics Committee at the Medical Faculty of the University of Rzeszów. A written consent from all participants was obtained prior to the study. Information regarding the birth date and the participants' level of ID was obtained from the medical files kept by the school nurses (a certificate of disability issued by the Disability Evaluation Board, at the Psychological and Pedagogical Counseling Center). The anthropometric measurements were carried out at schools, in nurses' offices. All measurements were taken between 10:00 a.m. and 12:00 a.m.

3.1. Participants. The study group consisted of students with ID aged 7-18, who were enrolled in public special education schools in southeastern Poland in the school year 2013/2014. The invitation to participate in the study was sent to all parents of children attending special schools in southeastern Poland ( $n=2282$ ). Approximately 908 parents gave consent to participate in the study. Of those, 340 were excluded from the study due to age: $<7$ yrs or $>18$ yrs $(n=59)$, taking medication affecting $\mathrm{BP}(n=21)$, functional state that does not allow for self-maintenance of standing position $(n=16)$, lack of cooperation or strong anxiety of the examination $(n=$ 28 ), being absent from school on test days $(n=53)$, and failure to return or incompletely completed survey $(n=163)$. Ultimately, the study group consisted of 568 students.

The control group consisted of students without ID attending randomly selected primary, middle and secondary schools in southeastern Poland. The invitation to participate in the study was sent to 3500 parents of students from the randomly selected schools. 1833 parents agreed for the child's participation in the study. Of these, 568 students were excluded due to age: $<7$ yrs or $>18$ yrs $(n=2)$, taking medication affecting $\mathrm{BP}(n=7)$, functional state that does not allow for self-maintenance of standing position $(n=1)$; lack of desire to participate in study or strong anxiety before the examination $(n=6)$, being absent from school on test days ( $n=77$ ), and failure to return or incompletely completed survey $(n=475)$. Out of 1265 tested students, 568 students were selected to the control group (age and sex adjustment). The students sampling to the control group was performed using Statistica software, sampling without replacement.

3.2. Body Height and Body Mass. Body height was measured with an accuracy of $0.1 \mathrm{~cm}$ using the PORTSTAND 210 portable stadiometer. The measurement was performed under standard conditions, in an upright position, barefoot.

The body mass was assessed with the accuracy of $0.1 \mathrm{~kg}$ using a body composition analyzer (BC-420 SMA, Tanita). The subjects were weighed in underwear, barefoot.

Body mass index (BMI) was calculated by dividing the body mass (in kg) by the height (in meters) squared (BMI = body mass/body height ${ }^{2}$ ). Based on BMI values, the BMI centile of individual students was calculated. BMI centile charts specific for age, sex, and body height (which were developed in the framework of the Polish project entitled "Developing standards of blood pressure in children and adolescents in Poland, OLAF") were used [21]. Based on the percentile values, the subjects were assigned to the following categories: obesity (BMI $\geq 95$ th percentile), overweight (BMI $\geq 85$ th percentile and $<95$ th percentile), healthy weight (BMI $<$ 85th percentile and $\geq 5$ th percentile), and underweight $(\mathrm{BMI}<5$ th percentile) $[22]$.

3.3. Arterial Blood Pressure. BP was measured three times with an aneroid sphygmomanometer in accordance with the current NHBPEP guidelines [23]. According to recent research result, the aneroid device has better accuracy than the digital device as compared to mercury sphygmomanometer and should be used for proper and better management. It has been found that the agreement between the mercury and aneroid sphygmomanometer in classifying hypertension is very high (kappa $=0.881, p<0.001)$. This suggests the greater ability of the aneroid instruments in classifying an individual as hypertensive or normotensive. In the validity analysis, it has been studied whether the aneroid and digital devices produced accurate results (one that lacked systematic error) by calculating sensitivity, specificity, positive, and negative predictive value, the mercury device being considered as a gold standard. All the indicators showed better results for aneroid device in comparison to the digital device [24].

BP was measured by trained staff predominantly by using aneroid sphygmomanometers recalibrated as needed by bioengineering services. Based on SBP and DBP, blood pressure centiles were estimated. The centile charts developed in the framework of the OLAF project were used [25]. Based on the percentile values obtained, the subjects were assigned to the following categories: normotension (BP was under the 90th percentile), prehypertension ( $\mathrm{BP} \geq 90$ th percentile or $\geq 120 / 80 \mathrm{mmHg}$, but $<95$ th percentile for age, sex, and 
height), and HPT (BP $\geq 95$ th percentile and/or the use of antihypertensive medication) [23].

3.4. Physical Activity Level and Screen Time. Physical Activity Questionnaire for Older Children (PAQ-C) and Physical Activity Questionnaire for Adolescent (PAQ-A) were used to assess the physical activity of children and adolescents. The questionnaires serve to assess the overall level of physical activity in children and adolescents during a school year. Both questionnaires include questions about physical activity undertaken in the past 7 days. The questionnaires cover questions about sports, games, and physical activity at school and during leisure, including weekends. Every question is scored on a 5 -point scale (1 to 5 points), with higher scores representing higher level of physical activity [26]. The selfreport PAQ-C and PAQ-A are valid, feasible, and costeffective tools to evaluate physical activity in youth and are regarded as some of the most suitable self-report tools for examining physical activity in these populations [27]. These questionnaires have been used to test for multiple psychometric properties, that is, item and scale, internal consistency, test-retest reliability, convergent validity, construct validity, and sensitivity to gender and age differences [28-31]. All of these properties have been reported as acceptable to good. The PAQ-A has been validated against objectively measured physical activity (such as accelerometers) $(r=0.33-0.63)$ and other self-reported measures of physical activity $(r=$ 0.73) [31,32]. Construct validity of the PAQ-C has been demonstrated through correlations with aerobic fitness $(r=$ $0.28)$ and perceptions of athletic competence $(r=0.48)$ [28]. Acceptable test-retest reliability and internal consistency have also been demonstrated for the PAQ-C and PAQ-A [30, 32].

Based on the value of the final PAQ score, the subjects were classified into three groups. Scores $\leq 2.3$, from 2.4 to 3.7 and $\geq 3.8$ pts represented the categories "low," "moderate," and "high" level of physical activity, respectively [30].

Total screen time (hours per day) was calculated as the average time spent on the following activities: TV/videos viewing, computer usage (both entertainment and homework), and using video games in week days and weekends.

Total time spent on sedentary activities was estimated. According to the international screen time recommendations, screen time was divided into two categories: (i) $<2 \mathrm{~h} /$ day and (ii) $\geq 2 \mathrm{~h} /$ day [5].

Information about physical activity and screen time in younger participants without ID ( 7 to 13 yrs) was reported by their parents as evidence indicates that children under 9 years of age have no cognitive ability to accurately recall or evaluate their physical activity [33]. All necessary data relating to participants with ID were collected from their parents or guardians.

3.5. Data Analysis. Descriptive statistics was used in the analysis: mean/standard deviation (SD). Mann-Whitney $U$ test (for binary variables) and Kruskal-Wallis test (for variables above two categories) were used to examine differences between independent quantitative variables. The selection of nonparametric tests resulted from lack of normality of variables (verified by Kolmogorov-Smirnov and Shapiro-Wilk tests). To examine the significance of differences between nominal variables, the independence test $\chi 2$ was used. The odds ratio (OR) was also used to discuss the frequency of a given variable. In order to determine the factors influencing the occurrence of hypertension in the study group multinomial logistic regression was used (progressive step method). The significance level was adopted at $p<0.05$. Calculations were performed using IBM SPSS Statistics 20 .

\section{Results}

The analyses were carried out for 568 students with ID (283 girls, 285 boys), aged 7-18, as well as 568 controls without ID, matched for age and sex. The distribution of age, sex, anthropometric data, level of physical activity, and screen time in both groups of subjects is presented in Table 1. The level of physical activity in the study group was significantly lower than in the control group (1.99 vs. 3.02 PAQ score, resp.). Most students with ID (70.4\%) had low levels of physical activity, and none of the students attained high physical activity level. Screen time during school days in children and adolescents with ID was significantly longer than in their peers without ID ( 3.38 versus $2.27 \mathrm{~h} /$ day), while on weekends it was comparable in both groups.

Table 2 shows the values of the odds ratios for the prevalence of HPT, depending on the level of physical activity. The students with ID with low physical activity level have a greater risk of HPT than the students with moderate levels of physical activity $(\mathrm{OR}=4.40)$. This relationship was stronger in the control group $(\mathrm{OR}=5.04)$; however, the reference group in this case were the subjects with high level of physical activity (not moderate as in the case of study group).

Table 3 presents the values of odds ratios of the prevalence of HPT in relation to screen time. The students with ID whose screen time was $\geq 2 \mathrm{~h} /$ day during both school days and weekends were more likely to have HPT $(\mathrm{OR}=2.21$ and 2.24 , resp.) than students whose screen time was $<2 \mathrm{~h} /$ day. There was a slightly higher risk of HPT $(\mathrm{OR}=2.74)$ in the group of students without ID who had a screen time $\geq 2 \mathrm{~h}$ /day during school days.

The findings presented in Table 4 are related only to the children and adolescents with ID. The results of multinomial logistic regression indicated that boys, the adolescents aged 14-18 yrs, the individuals with obesity, and those with screen time $\geq 2 \mathrm{~h} /$ day had higher risk of HPT; however, obesity proved to be the strongest factor (Table 4).

\section{Discussion}

Many studies have examined the association between physical activity, screen time, and HPT in children and adolescents [34-36], but to date, there have been no data on children and adolescents with ID. Therefore, the purpose of this study was to analyze the relationship between the level of physical activity and screen time with the prevalence of HPT in children and adolescents with ID and comparison with their peers without ID. In this study, we demonstrated that students with ID with low physical activity level were over 4 times more likely to develop HPT compared to the subjects with 
TABLE 1: Detailed characteristics of the groups.

\begin{tabular}{|c|c|c|c|}
\hline Variable & Study group (with ID) & Control group (without ID) & $p$ \\
\hline \multicolumn{4}{|l|}{ Age (years) } \\
\hline $7-13^{\mathrm{a}}$ & $346(61.0)$ & $346(61.0)$ & 1.000 \\
\hline $14-18^{\mathrm{a}}$ & $221(39.0)$ & $221(39.0)$ & \\
\hline \multicolumn{4}{|l|}{$\operatorname{Sex}^{\mathrm{a}}$} \\
\hline Girl & $283(49.8)$ & $283(49.8)$ & 1.000 \\
\hline Boy & $285(50.2)$ & $285(50.2)$ & \\
\hline Body height percentile $^{\mathrm{b}}$ & $33.99(31,14)$ & $44.77(28.88)$ & $<0.001^{*}$ \\
\hline BMI percentile $^{\mathrm{b}}$ & $55.18(33.79)$ & $48.41(31.67)$ & $0.001^{*}$ \\
\hline $\mathrm{SBP}(\mathrm{mm} \mathrm{Hg})^{\mathrm{b}}$ & $118.51(11.22)$ & $115.99(9.11)$ & $0.001^{*}$ \\
\hline $\mathrm{DBP}(\mathrm{mm} \mathrm{Hg})^{\mathrm{b}}$ & $68.79(5.98)$ & $68.62(4.32)$ & 0.252 \\
\hline SBP percentile ${ }^{b}$ & $74.81(23.67)$ & $69.46(22.66)$ & $<0.001^{*}$ \\
\hline DBP percentile ${ }^{b}$ & 74.35 (17.79) & $75.03(15.50)$ & 0.935 \\
\hline \multicolumn{4}{|l|}{ Level of ID ${ }^{\mathrm{a}}$} \\
\hline Mild & $278(24.5)$ & $\mathrm{n} / \mathrm{a}$ & $\mathrm{n} / \mathrm{a}$ \\
\hline Moderate & $239(21.1)$ & & \\
\hline Severe & $50(4.4)$ & & \\
\hline PAQ score ${ }^{b}$ & $1.99(0.74)$ & $3.02(0.81)$ & $<0.001^{*}$ \\
\hline \multicolumn{4}{|l|}{ Level of physical activity ${ }^{a}$} \\
\hline Low & $399(70.4)$ & $124(21.9)$ & \\
\hline Moderate & $168(29.6)$ & $351(61.9)$ & $<0.001^{*}$ \\
\hline High & $0(0.0)$ & $92(16.2)$ & \\
\hline Screen time on school days $(\mathrm{h} / \text { day })^{\mathrm{b}}$ & $3.38(1.66)$ & $2.27(1.19)$ & $<0.001^{*}$ \\
\hline Screen time on weekends $(\mathrm{h} / \text { day })^{\mathrm{b}}$ & $3.85(1.48)$ & $3.59(1.62)$ & 0.016 \\
\hline
\end{tabular}

TABLE 2: Odds ratio for hypertension prevalence depending on physical activity level.

\begin{tabular}{|c|c|c|c|c|c|c|c|c|c|}
\hline \multirow{3}{*}{ Classification of blood pressure } & \multicolumn{9}{|c|}{ Level of physical activity } \\
\hline & \multicolumn{2}{|c|}{ High } & \multicolumn{3}{|c|}{ Moderate } & \multicolumn{3}{|c|}{ Low } & \multirow[t]{2}{*}{$p$} \\
\hline & $n$ & $\%$ & $n$ & $\%$ & OR $(95 \% \mathrm{CI})$ & $n$ & $\%$ & OR $(95 \% \mathrm{CI})$ & \\
\hline \multicolumn{10}{|c|}{ Study group (with ID) } \\
\hline Normotension & - & - & 125 & 74.4 & $(\mathrm{REF})$ & 220 & 55.1 & $0.42(0.28-0,63)$ & $<0.001^{*}$ \\
\hline Prehypertension & - & - & 32 & 19.0 & $(\mathrm{REF})$ & 85 & 21.3 & $1.15(0.73-1.81)$ & 0.545 \\
\hline Hypertension & - & - & 11 & 6.5 & (REF) & 94 & 23.6 & $4.40(2.29-8.46)$ & $<0.001^{*}$ \\
\hline \multicolumn{10}{|c|}{ Control group (without ID) } \\
\hline Normotension & 81 & 88.0 & 284 & 80.9 & $0.58(0.29-1.14)$ & 82 & 66.1 & $0.27(0.13-0.55)$ & $0.001^{*}$ \\
\hline Prehypertension & 8 & 8.7 & 56 & 16.0 & $1.99(0.91-4.35)$ & 24 & 19.4 & $2.52(1.08-5.90)$ & 0.095 \\
\hline Hypertension & 3 & 3.3 & 11 & 3.1 & $0.96(0.26-3.51)$ & 18 & 14.5 & $5.04(1.44-17.66)$ & $<0.001^{*}$ \\
\hline
\end{tabular}

REF: reference group. ${ }^{*}$ Statistically significant results. ID: intellectual disability.

moderate levels of physical activity. Screen time also proved to be important predictor of HPT. We showed that the risk of HPT in subjects with ID who spent at least 2 hours per day on sedentary activities was more than twice as high as in the subjects with shorter time. According to our knowledge, the results presented in our research are the first concerning the relationship between the physical activity and screen time with prevalence HPT in children and adolescents with ID. Therefore, it is impossible to compare our results with the results of other authors. However, we conducted multivariate analysis to find out which factors have the strongest impact on the prevalence of HPT in children and adolescents with ID. We have demonstrated that the prevalence of HPT was related to gender, age, BMI category, and screen time, and the strongest determinant was presence of obesity.

These findings suggest that proactive interventions should be introduced to reduce the prevalence of HPT in this population. Individuals with ID should be included in activities to increase physical activity and reduce weight. These activities should also be addressed to parents or carers 
TABLE 3: Odds ratio for hypertension prevalence in the study groups depending on screen time.

\begin{tabular}{|c|c|c|c|c|c|c|c|c|}
\hline \multirow{4}{*}{ Classification of blood pressure } & \multicolumn{5}{|c|}{ Study group (with ID) } & \multicolumn{3}{|c|}{ Control group (without ID) } \\
\hline & \multirow{3}{*}{$\begin{array}{c}<2 \text { h/day } \\
n(\%)\end{array}$} & \multirow{2}{*}{\multicolumn{2}{|c|}{$\geq 2$ h/day }} & \multicolumn{2}{|c|}{ Screen time } & \multirow{2}{*}{\multicolumn{2}{|c|}{$\geq 2 \mathrm{~h} /$ day }} & \multirow[b]{3}{*}{$p$} \\
\hline & & & & & $<2$ h/day & & & \\
\hline & & $n(\%)$ & $\begin{array}{c}\text { OR } \\
(95 \% \mathrm{CI})\end{array}$ & $p$ & $n(\%)$ & $n(\%)$ & $\begin{array}{c}\text { OR } \\
(95 \% \mathrm{CI})\end{array}$ & \\
\hline \multicolumn{9}{|c|}{ Screen time on school days } \\
\hline Normotension & $134(67.0)$ & $211(57.5)$ & $\begin{array}{c}0.67 \\
(0.46-0.96)\end{array}$ & $0.027^{*}$ & $231(80.8)$ & $216(76.9)$ & $\begin{array}{c}0.79 \\
(0.53-1.19)\end{array}$ & 0.256 \\
\hline Prehypertension & $43(21.5)$ & $74(20.2)$ & $\begin{array}{c}0.92 \\
(0.60-1.41)\end{array}$ & 0.707 & $46(16.1)$ & $42(14.9)$ & $\begin{array}{c}0.92 \\
(0.58-1.45)\end{array}$ & 0.709 \\
\hline Hypertension & $23(11.5)$ & $82(22.3)$ & $\begin{array}{c}2.21 \\
(1.34-3.65) \\
\end{array}$ & $0.002^{*}$ & $9(3.1)$ & $23(8.2)$ & $\begin{array}{c}2.74 \\
(1.25-6.04) \\
\end{array}$ & $0.009^{*}$ \\
\hline \multicolumn{9}{|c|}{ Screen time on weekends } \\
\hline Normotension & $68(69.4)$ & $277(59.1)$ & $\begin{array}{c}0.64 \\
(0.40-1.02)\end{array}$ & 0.057 & $104(81.9)$ & $343(78.0)$ & $\begin{array}{c}0.78 \\
(0.47-1.30)\end{array}$ & 0.339 \\
\hline Prehypertension & $20(20.4)$ & $97(20.7)$ & $\begin{array}{c}1.02 \\
(0,59-1.74)\end{array}$ & 0.951 & $18(14.2)$ & $70(15.9)$ & $\begin{array}{c}1.15 \\
(0,65-2.01)\end{array}$ & 0.634 \\
\hline Hypertension & $10(10.2)$ & $95(20.3)$ & $\begin{array}{c}2.24 \\
(1.12-4.46)\end{array}$ & $0.020^{*}$ & $5(3.9)$ & $27(6.1)$ & $\begin{array}{c}1.60 \\
(0.60-4.23)\end{array}$ & 0.344 \\
\hline
\end{tabular}

ID: intellectual disability. ${ }^{*}$ Statistically significant results.

TABLE 4: Variables influencing prevalence of hypertension in children and adolescents with ID: multinomial logistic regression (progressive step method).

\begin{tabular}{|c|c|c|}
\hline Hypertension $(0-$ no; 1 -yes $)$ & OR $(95 \% \mathrm{CI})$ & $p$ \\
\hline \multicolumn{3}{|l|}{ Sex $(0$, girl $)$} \\
\hline Boy & $2.24(1.35-3.72)$ & $0.002^{*}$ \\
\hline \multicolumn{3}{|l|}{ Age $(0-7-13$ years $)$} \\
\hline $14-18$ years & $3.79(2.30-6.25)$ & $0.000^{*}$ \\
\hline \multicolumn{3}{|c|}{ Body weight classification ( 0 -healthy weight) } \\
\hline Underweight & $0.32(0.07-1.40)$ & 0.131 \\
\hline Overweight & $1.73(0.88-3.39)$ & 0.111 \\
\hline Obesity & $7.88(4.38-14.19)$ & $0.000^{*}$ \\
\hline \multicolumn{3}{|c|}{ Screen time on school days $(0-<2 \mathrm{~h} /$ day $)$} \\
\hline$\geq 2 \mathrm{~h} /$ day & $1.83(1.02-3.29)$ & $0.044^{*}$ \\
\hline \multicolumn{3}{|c|}{ Screen time on weekends $(0-<2 \mathrm{~h} /$ day $)$} \\
\hline$\geq 2$ h/day & $2.20(1.00-4.85)$ & 0.051 \\
\hline
\end{tabular}

${ }^{*}$ Reference groups are the groups indicated in parentheses. The model included age, sex, level of disability, BMI categories, physical activity level, and screen time.

of children to raise their awareness about the needs and benefits of lifestyle change in this population with special needs.

The present study indicates significantly lower levels of physical activity among students with ID compared to their peers without ID (1.99 versus 3.02 PAQ score, resp.). Slightly more than $70 \%$ of children and adolescents with ID had low physical activity levels, moderate, approx. 30\%, and no one had a high level of physical activity. Students without ID were much more active. Nearly $80 \%$ of this group had moderate or high levels of physical activity. The results of this study support previous findings. Lin et al. reported that only $8 \%$ of adolescents with ID met the national physical activity recommendation in Taiwan which suggests 30 minutes of physical activity at least 3 times a week. They also observed that the increase in the level of ID was accompanied with the significant reduction in the level of physical activity. Physical activity of young people varied depending on the level of parental education and material status. The higher the education and monthly income declared by the parents is, the more often the youth undertook regular physical activity [11]. Emerson's study showed that even fewer (4\%) individuals with ID aged 16-24 years in Northern England met criteria for being "physically active" [37]. Mikulovic et al. showed that students with ID spent on average 4.5 hours per week on motor activity and in their peers without ID it was 7.5 hours per week [38]. Other researchers also reported that very few or no children with ID reached recommended levels 
of physical activity estimated via self-reported questionnaires [39] or accelerometers [40]. Frey et al. used accelerometers to assess the level of physical activity in four different situations: during physical education class, breaks, after school, and weekends. The level of physical activity in the children with ID was significantly lower in every analyzed case compared to the students without ID [41]. In turn, Pan et al. showed that the level of physical activity in the adolescents with ID during physical education class was at a comparable level to the physical activity level of their peers without ID. However, during the break, the students with ID were significantly less active than their peers without ID [12]. According to Einarsson et al., the time spent in moderate to vigorous physical activity among children with ID was only $41 \%, 50 \%$, and $32 \%$ of that of children without ID during entire weekday, school hours, and after school hours, respectively [10]. It was also shown that children with ID are less likely to participate in out-of-school sports than their peers without ID [42, 43]. To overcome the most prominent barriers in taking up physical activity in people with ID (such as health problems, lack of motivation) it is extremely important to start to reduce or eliminate environmental barriers. In addition, healthcare professionals should advise their regular patients to become physically active by taking regular physical activity such as walking, jogging, cycling, swimming, and sports and to improve their fitness for the primary prevention of HPT.

Data on sedentary behavior among the students with ID is ambiguous. The results of our study indicate that the average screen time in the children and adolescents with ID was 3.38 hours a day during school days and 3.85 hours a day during weekends. Among students without ID this time was lower and amounted to 2.27 and 3.58 hours, respectively. Similar results were obtained by Einarsson et al. who reported that non-ID children are $44 \%$ more active and $24 \%$ less sedentary than children with ID during the entire weekday [10]. Prior studies had also shown that individuals with ID were more likely to lead sedentary lifestyles and were less active than their counterparts without ID $[44,45]$. On the other hand, Mikulovic et al. indicated that the average screen time among the adolescents with ID was 26.6 hours per week and was close to that of the peers without ID [38]. Also Foley and McCubbin did not observe the difference in time devoted to watching TV or computer games between ID and non-ID individuals. Time spent on watching TV in children with ID was longer, but not significantly different, than time spent on viewing TV in children without ID [46]. The divergence of the above-mentioned results may be due to differences in the level of ID in the studied individuals. To better understand the sedentary behavior of the individuals with ID, it is necessary to examine a large group across all severity levels of ID.

Our findings raise serious concerns and corroborate the high prevalence of both risk factors of HPT: low physical activity and high screen time among children and adolescents with ID. There is still a need to promote physical activity in childhood and adolescence, and the results of our research may help to develop effective interventions for this population, especially as the topic of physical activity in the individuals with ID is significantly underresearched [47]. There is ample evidence that increase of physical activity has a positive effect on BP. Results of randomized controlled trial of exercise intervention including 60 minutes of physical activity 3 times a week for 3 months showed reduction in office and $24 \mathrm{~h}$ ambulatory BP in the physical activity group compared with no intervention. After three months, BP in the intervention group was lower by about $6 \mathrm{~mm} \mathrm{Hg}$ for clinic SBP and DBP, and $10.7 \mathrm{~mm} \mathrm{Hg}$ for 24-hour ambulatory SBP. A follow-up after 6 months indicated that the intervention group had improvements in carotid intima-media thickness and arterial stiffness [48]. The results of systematic review and meta-analysis have also confirmed that increased physical activity leads to a significant BP reduction in patients with established HPT [49].

Our study indicated the importance of promoting educational programs on healthy lifestyles among young population with ID. Future research should focus on developing effective strategies and physical activity programs tailored for individuals with ID, since physical activity is of great importance, given the established relationship between physical activity and health.

5.1. Limitation. This study is not without limitations. The assessment of the level of physical activity using the selfassessment method (PAQ-C, PAQ-A) can be considered as a study limitation. We decided to use this method, instead of accelerometry-based measures (the golden standard for assessing the level of physical activity), due to a large number of the study and control groups. However, the results of the study indicate that the PAQ-C and PAQ-A are reliable and reproducible tools used to assess physical activity in children and adolescents. In addition, we ensured that questionnaires were properly completed, under the supervision of researchers previously trained for their application.

\section{Conclusions}

Low level of physical activity and long screen time were associated with significantly higher HPT risk among the children and adolescents with ID.

\section{Conflicts of Interest}

The authors declare that there are no conflicts of interest regarding the publication of this paper.

\section{References}

[1] I. Lee, E. J. Shiroma, F. Lobelo et al., "Effect of physical inactivity on major non-communicable diseases worldwide: an analysis of burden of disease and life expectancy," The Lancet, vol. 380, no. 9838, pp. 219-229, 2012.

[2] K. M. Diaz and D. Shimbo, "Physical activity and the prevention of hypertension," Current Hypertension Reports, vol. 15, no. 6, pp. 659-668, 2013.

[3] J. M. Dionne, K. C. Harris, G. Benoit et al., "Hypertension Canada's 2017 guidelines for the diagnosis, assessment, prevention, and treatment of pediatric hypertension," Canadian Journal of Cardiology, vol. 33, no. 5, pp. 577-585, 2017. 
[4] P. C. Hallal, L. B. Andersen, F. C. Bull et al., "Global physical activity levels: surveillance progress, pitfalls, and prospects," The Lancet, vol. 380, no. 9838, pp. 247-257, 2012.

[5] American Academy of Pediatrics Committee on Public Education, "Children, adolescents, and television," Pediatrics, vol. 107, no. 2, pp. 423-426, 2001.

[6] S. Aznar, M. T. Lara, A. Queralt, and J. Molina-Garcia, "Psychosocial and environmental correlates of sedentary behaviors in spanish children," BioMed Research International, vol. 2017, Article ID 4728924, 6 pages, 2017.

[7] M. S. Tremblay, A. G. LeBlanc, M. E. Kho et al., "Systematic review of sedentary behaviour and health indicators in schoolaged children and youth," International Journal of Behavioral Nutrition and Physical Activity, vol. 8, article 98, 2011.

[8] D. Martinez-Gomez, J. Tucker, K. A. Heelan, G. J. Welk, and J. C. Eisenmann, "Associations between sedentary behavior and blood pressure in young children," JAMA Pediatrics, vol. 163, no. 8, pp. 724-730, 2009.

[9] J. C. K. Wells, P. C. Hallal, F. F. Reichert, A. M. B. Menezes, C. L. P. Araújo, and C. G. Victora, "Sleep patterns and television viewing in relation to obesity and blood pressure: Evidence from an adolescent Brazilian birth cohort," International Journal of Obesity, vol. 32, no. 7, pp. 1042-1049, 2008.

[10] I. Einarsson, E. Jóhannsson, D. Daly, and S. Á. Arngrímsson, "Physical activity during school and after school among youth with and without intellectual disability," Research in Developmental Disabilities, vol. 56, pp. 60-70, 2016.

[11] J.-D. Lin, P.-Y. Lin, L.-P. Lin, Y.-Y. Chang, S.-R. Wu, and J.-L. Wu, "Physical activity and its determinants among adolescents with intellectual disabilities," Research in Developmental Disabilities, vol. 31, no. 1, pp. 263-269, 2010.

[12] C.-Y. Pan, C.-W. Liu, I. C. Chung, and P.-J. Hsu, "Physical activity levels of adolescents with and without intellectual disabilities during physical education and recess," Research in Developmental Disabilities, vol. 36, pp. 579-586, 2015.

[13] A. C. Phillips and A. J. Holland, "Assessment of objectively measured physical activity levels in individuals with intellectual disabilities with and without Down's syndrome," PLoS ONE, vol. 6, no. 12, Article ID e28618, 2011.

[14] L. Bossink, A. A. van der Putten, and C. Vlaskamp, "Understanding low levels of physical activity in people with intellectual disabilities: A systematic review to identify barriers and facilitators," Research in Developmental Disabilities, vol. 68, pp. 95-110, 2017.

[15] C. Maïano, "Prevalence and risk factors of overweight and obesity among children and adolescents with intellectual disabilities," Obesity Reviews, vol. 12, no. 3, pp. 189-197, 2011.

[16] J. Wyszyńska, J. Podgórska-Bednarz, J. Leszczak, and A. Mazur, "Prevalence of hypertension and prehypertension in children and adolescents with intellectual disability in southeastern Poland," Journal of Intellectual Disability Research, vol. 61, no. 11, pp. 995-1002, 2017.

[17] P.-Y. Lin, L.-P. Lin, and J.-D. Lin, "Hypertension, hyperglycemia, and hyperlipemia among adolescents with intellectual disabilities," Research in Developmental Disabilities, vol. 31, no. 2, pp. 545-550, 2010.

[18] X. Chen and Y. Wang, "Tracking of blood pressure from childhood to adulthood: A systematic review and meta-regression analysis," Circulation, vol. 117, no. 25, pp. 3171-3180, 2008.

[19] P. W. Franks, R. L. Hanson, W. C. Knowler, M. L. Sievers, P. H. Bennett, and H. C. Looker, "Childhood obesity, other cardiovascular risk factors, and premature death," The New England Journal of Medicine, vol. 362, no. 6, pp. 485-493, 2010.

[20] W. Bryl, K. Matuszak, and K. Hoffmann, "Physical activity of children and adolescents with intellectual disabilities-a public health problem," Hygeia Public Health, vol. 48, no. 1, pp. 1-5, 2013.

[21] Z. Kułaga, A. Różdżyńska, and I. Palczewska, "Centile grids for body height,mass as well as bodymass index, in Polish children and adolescents-OLAF study reportt," Standardy Medyczne, vol. 7, pp. 690-700, 2010.

[22] D. K. Eaton, L. Kann, S. Kinchen et al., "Youth risk behawior surveillanceUnited states," MMWR Surveillance Summaries, vol. 57, no. 4, pp. 1-131, 2007.

[23] National High Blood Pressure Education Program Working Group on High Blood Pressure in Children and Adolescents, "Fourth report on the diagnosis, evaluation and treatment of high blood pressure in children and adolescents," Pediatrics, vol. 114, Suplement 2, pp. 555-576, 2004, https://www.ncbi.nlm.nih .gov/pubmed/15286277.

[24] B. Shahbabu, A. Dasgupta, K. Sarkar, and S. K. Sahoo, "Which is more accurate in measuring the blood pressure? A digital or an aneroid sphygmomanometer," Journal of Clinical and Diagnostic Research, vol. 10, no. 3, pp. LC11-LC14, 2016.

[25] Z. Kułaga, M. Litwin, A. Grajda et al., "Distribution of blood pressure in school-aged children and adolescents reference population," Standardy Medyczne, vol. 7, pp. 100-111, 2010.

[26] K. C. Kowalski, P. R. E. Crocker, and R. M. Donen, The Physical Activity Questionnaire for Older Children (PAQ-C) and Adolescents (PAQ-A) Manual, College of Kinesiology, University of Saskatchewan, Canada, 2004.

[27] S. J. H. Biddle, T. Gorely, N. Pearson, and F. C. Bull, "An assessment of self-reported physical activity instruments in young people for population surveillance: Project ALPHA," International Journal of Behavioral Nutrition and Physical Activity, vol. 8, article no. 1, 2011.

[28] K. C. Kowalski, P. R. E. Crocker, and R. A. Faulkner, "Validation of the physical activity questionnaire for older children," Pediatric exercise science, vol. 9, no. 2, pp. 174-186, 1997.

[29] K. C. Kowalski, P. R. E. Crocker, and N. P. Kowalski, "Convergent validity of the Physical Activity Questionnaire for Adolescents," Pediatric exercise science, vol. 9, no. 4, pp. 342-352, 1997.

[30] P. R. E. Crocker, D. A. Bailey, R. A. Faulkner, K. C. Kowalski, and R. Mcgrath, "Measuring general levels of physical activity: Preliminary evidence for the physical activity questionnaire for older children," Medicine \& Science in Sports \& Exercise, vol. 29, no. 10, pp. 1344-1349, 1997.

[31] K. F. Janz, E. M. Lutuchy, P. Wenthe, and S. M. Levy, "Measuring activity in children and adolescents using self-report: PAQ-C and PAQ-A," Medicine \& Science in Sports \& Exercise, vol. 40, no. 4, pp. 767-772, 2008.

[32] D. Martinez-Gómez, V. Martinez-de-Haro, T. Pozo et al., "Reliability and validity of the PAQ-A questionnaire to assess physical activity in Spanish adolescents," Revista Española de Salud Pública, vol. 83, no. 3, pp. 427-439, 2009.

[33] W. H. Saris, "Habitual physical activity in children: methodology and findings in health and disease," Medicine Science in Sport Exercise, vol. 18, pp. 253-263, 1986.

[34] B. Gopinath, L. L. Hardy, E. Teber, and P. Mitchell, "Association between physical activity and blood pressure in prepubertal children," Hypertension Research, vol. 34, no. 7, pp. 851-855, 2011. 
[35] A. C. F. De Moraes, H. B. Carvalho, A. Siani et al., "Incidence of high blood pressure in children - Effects of physical activity and sedentary behaviors: The IDEFICS study: High blood pressure, lifestyle and children," International Journal of Cardiology, vol. 180, pp. 165-170, 2015.

[36] J. Väistö, A.-M. Eloranta, A. Viitasalo et al., "Physical activity and sedentary behaviour in relation to cardiometabolic risk in children: Cross-sectional findings from the Physical Activity and Nutrition in Children (PANIC) Study," International Journal of Behavioral Nutrition and Physical Activity, vol. 11, no. 1, article no. 55, 2014.

[37] E. Emerson, "Underweight, obesity and exercise among adults with intellectual disabilities in supported accomodation in Northern England," Journal of Intellectual Disability Research, vol. 49, no. 2, pp. 134-143, 2005.

[38] J. Mikulovic, A. Marcellini, R. Compte et al., "Prevalence of overweight in adolescents with intellectual deficiency. Differences in socio-educative context, physical activity and dietary habits," Appetite, vol. 56, no. 2, pp. 403-407, 2011.

[39] J. H. Rimmer and K. Yamaki, "Obesity and intellectual disability," Mental Retardation and Developmental Disabilities Research Reviews, vol. 12, no. 1, pp. 22-27, 2006.

[40] J. J. Peterson, K. F. Janz, and J. B. Lowe, "Physical activity among adults with intellectual disabilities living in community settings," Preventive Medicine, vol. 47, no. 1, pp. 101-106, 2008.

[41] G. C. Frey, H. I. Stanish, and V. A. Temple, "Physical activity of youth with intellectual disability: Review and research agenda," Adapted Physical Activity Quarterly, vol. 25, no. 2, pp. 95-117, 2008.

[42] M. King, N. Shields, C. Imms, M. Black, and C. Ardern, "Participation of children with intellectual disability compared with typically developing children," Research in Developmental Disabilities, vol. 34, no. 5, pp. 1854-1862, 2013.

[43] D. Abells, J. Burbidge, and P. Minnes, "Involvement of adolescents with intellectual disabilities in social and recreational activities," Developmental Disabilities, vol. 14, no. 2, pp. 88-94, 2008.

[44] R. J. Van Den Berg-Emons, M. A. Van Baak, L. Speth, and W. H. Saris, "Physical training of school children with spastic cerebral palsy: Effects on daily activity, fat mass and fitness," International Journal of Rehabilitation Research, vol. 21, no. 2, pp. 179-194, 1998.

[45] J. H. Rimmer, D. Braddock, and G. Fujiura, "Prevalence of obesity in adults with mental retardation: Implications for health promotion and disease prevention," Mental Retardation, vol. 31, no. 2, pp. 105-110, 1993.

[46] J. T. Foley and J. A. McCubbin, "An exploratory study of after-school sedentary behaviour in elementary school-age children with intellectual disability," Journal of Intellectual and Developmental Disability, vol. 34, no. 1, pp. 3-9, 2009.

[47] M. Lloyd, "Physical Activity of Individuals with Intellectual Disabilities: Challenges and Future Directions," Current Developmental Disorders Reports, vol. 3, no. 2, pp. 91-93, 2016.

[48] N. J. Farpour-Lambert, Y. Aggoun, L. M. Marchand, X. E. Martin, F. R. Herrmann, and M. Beghetti, "Physical activity reduces systemic blood pressure and improves early markers of atherosclerosis in pre-pubertal obese children," Journal of the American College of Cardiology, vol. 54, no. 25, pp. 2396-2406, 2009.

[49] T. Semlitsch, K. Jeitler, L. G. Hemkens et al., "Increasing physical activity for the treatment of hypertension: A systematic review and meta-analysis," Sports Medicine, vol. 43, no. 10, pp. 10091023, 2013. 


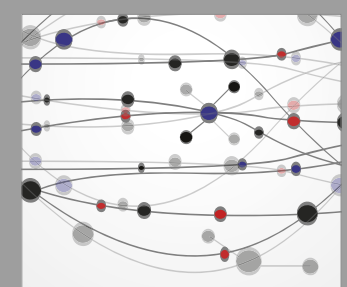

The Scientific World Journal
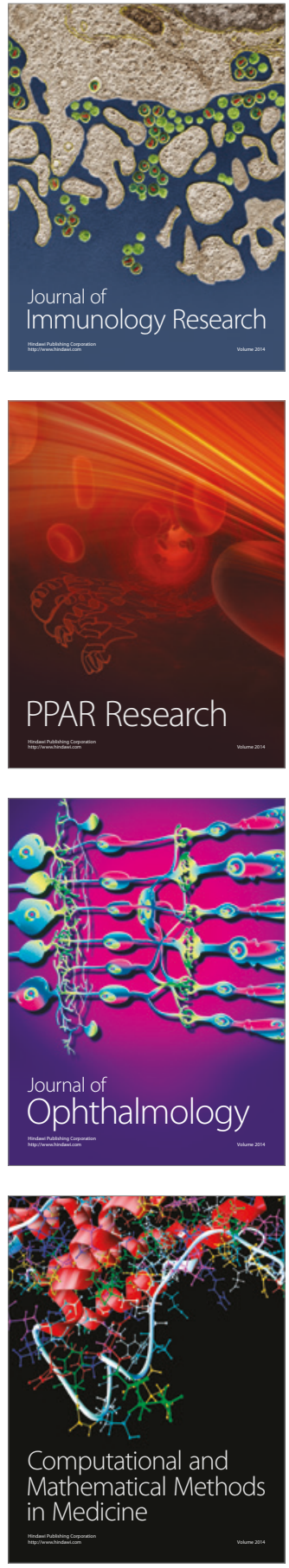

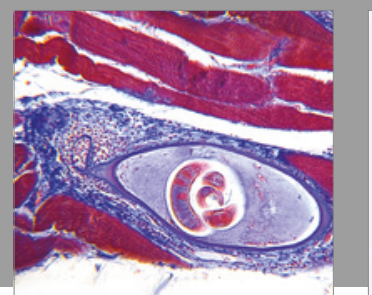

Gastroenterology Research and Practice
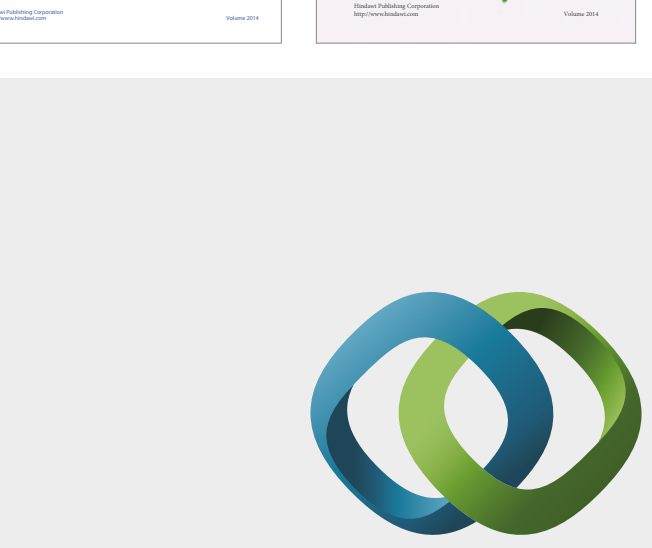

\section{Hindawi}

Submit your manuscripts at

https://www.hindawi.com
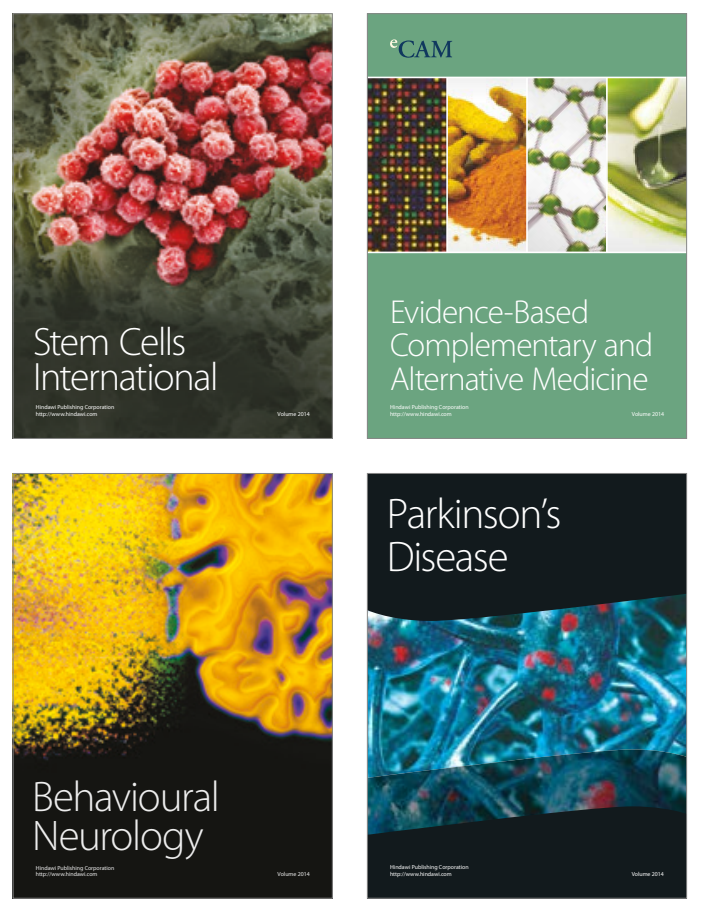
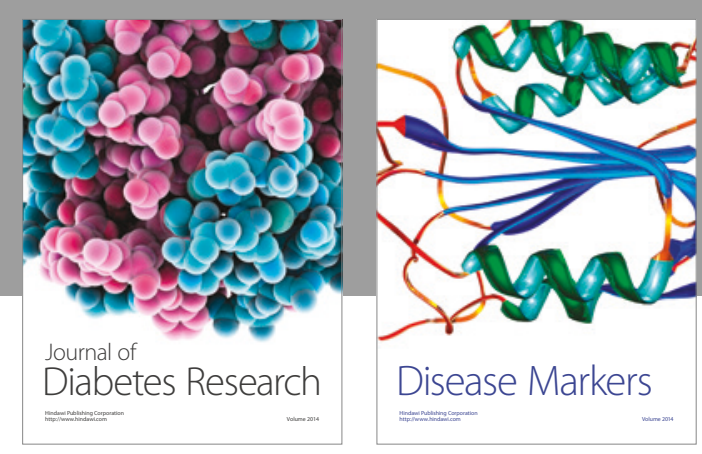

Disease Markers
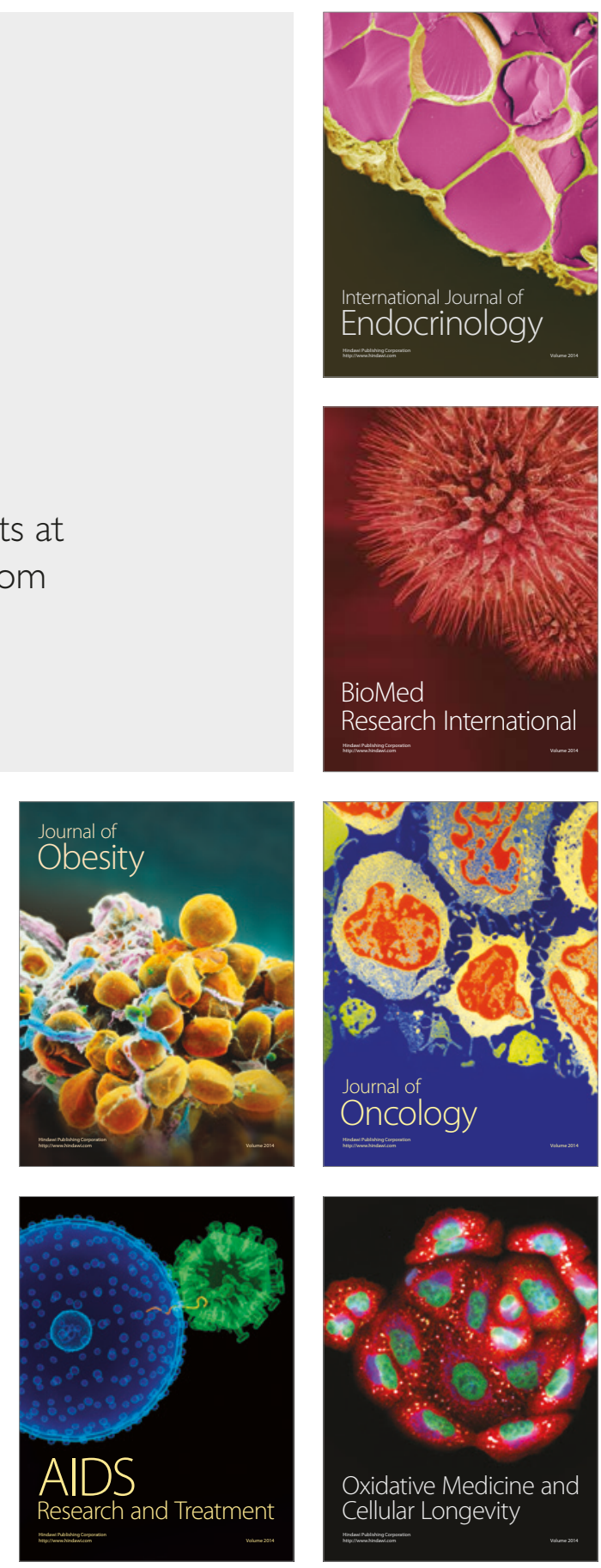